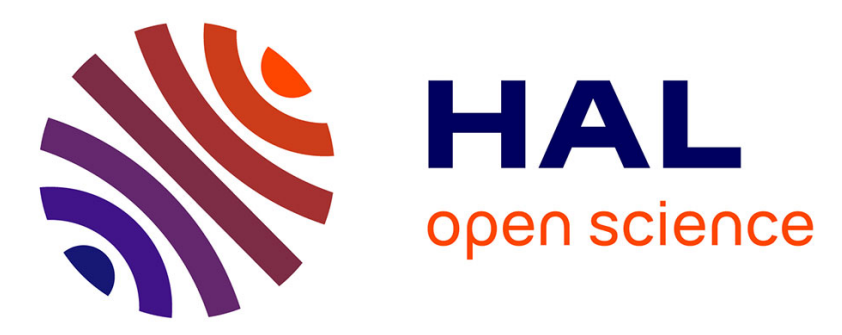

\title{
Abdominopelvic injuries due to road traffic accidents: Characteristics in a registry of 162,695 victims
}

Tristan Monchal, Amina Ndiaye, Blandine Gadegbeku, Etienne Javouhey, Olivier Monneuse

\section{- To cite this version:}

Tristan Monchal, Amina Ndiaye, Blandine Gadegbeku, Etienne Javouhey, Olivier Monneuse. Abdominopelvic injuries due to road traffic accidents: Characteristics in a registry of 162,695 victims. Traffic Injury Prevention, 2018, 19 (5), pp. 529-534. 10.1080/15389588.2018.1447669 . hal-01833422

\section{HAL Id: hal-01833422 https://hal.science/hal-01833422}

Submitted on 9 Jul 2018

HAL is a multi-disciplinary open access archive for the deposit and dissemination of scientific research documents, whether they are published or not. The documents may come from teaching and research institutions in France or abroad, or from public or private research centers.
L'archive ouverte pluridisciplinaire HAL, est destinée au dépôt et à la diffusion de documents scientifiques de niveau recherche, publiés ou non, émanant des établissements d'enseignement et de recherche français ou étrangers, des laboratoires publics ou privés. 


\section{Traffic Injury Prevention}

\section{Abdominopelvic injuries due to road traffic accidents: Characteristics in a registry of 162,695 victims}

Tristan Monchal, Amina Ndiaye, Blandine Gadegbeku, Etienne Javouhey \& Olivier Monneuse

To cite this article: Tristan Monchal, Amina Ndiaye, Blandine Gadegbeku, Etienne Javouhey \& Olivier Monneuse (2018) Abdominopelvic injuries due to road traffic accidents: Characteristics in a registry of 162,695 victims, Traffic Injury Prevention, 19:5, 529-534, DOI: 10.1080/15389588.2018.1447669

To link to this article: https://doi.org/10.1080/15389588.2018.1447669

Accepted author version posted online: 06

Mar 2018.

Published online: 18 Apr 2018.

Submit your article to this journal $₫$

Џ Article views: 83

View Crossmark data ¿ 


\title{
Abdominopelvic injuries due to road traffic accidents: Characteristics in a registry of 162,695 victims
}

\author{
Tristan Monchal $^{a}$, Amina Ndiaye ${ }^{b}$, Blandine Gadegbeku ${ }^{b}$, Etienne Javouhey ${ }^{b, c}$, and Olivier Monneuse ${ }^{d}$ \\ ${ }^{a}$ Department of General Surgery, Sainte Anne Military Hospital, Toulon, France; ${ }^{b}$ UMR Epidémiologique et de Surveillance Transport Travail \\ Environnement, IFSTTAR (French Institute of Science and Technology for Transport, Spatial Planning, Development and Networks), Université Lyon1, \\ UMR, Bron, France; 'Pediatric Intensive Care Unit, Hôpital Femme Mère Enfant, Hospices Civils de Lyon, Bron, France; ${ }^{\mathrm{d}}$ Emergency and Trauma Surgery \\ Department, Hôpital Édouard Herriot, Hospices Civils de Lyon, France
}

\begin{abstract}
Objective: Road traffic accidents (RTAs) are the first cause of abdominopelvic injuries (APIs). The objective of this study was to describe the characteristics and severity of APIs due to traffic accidents in a large French trauma registry and to identify risk factors for API.

Methods: All victims from the French Rhône registry of victims of RTAs were analyzed from 1996 to 2013. This registry contained data that were issued over a 20-year period from 245 medical departments, from prehospital care until re-adaptation, and forensic medicine departments. All APIs, defined as an injury between the diaphragm and the pelvic bone, were extracted and studied.

Results: Among 162,695 victims, 10,165 had an API (6.7\%). Accidents frequently involved young men and 2 cars. Mean Injury Severity Score (ISS) was 8.7. Mortality rate was 5.6\%. Soft tissue injuries largely predominated ( $n=6,388 ; 54.4 \%$ of patients). Overall, 2,322 victims had a pelvic bone injury. Internal abdominal organs were involved in 2,425 patients; the most frequent were the spleen, liver, and kidney. Wearing of the seat belt appeared to be a significant protective factor in API, including serious injuries. A partial analysis over the past 2 years among the most severe patients hospitalized in the intensive care unit indicated that nonoperative management was carried out in two thirds of the wounded. In uni- or multivariate analysis, sex, age, type of user, antagonist, time of occurrence, associated severe lesions, or wearing of the seat belt were statistically associated with the occurrence of API, highlighting a more dangerous user profile.

Conclusions: Abdominopelvic injuries concern a minority of road traffic injuries, but they are responsible for significant mortality. Large solid organs are the most frequently affected. Women drivers wearing a seat belt and driving in town during the day appear to be more protected against API.
\end{abstract}

\section{ARTICLE HISTORY}

Received 30 September 2017 Accepted 28 February 2018

\section{KEYWORDS}

Road traffic accident; abdominal trauma; pelvic trauma; trauma registry; Abbreviated Injury Scale

\section{Introduction}

Road traffic accidents (RTAs) are still the first cause of abdominopelvic injuries (APIs; Moore 2011; Smith et al. 2005). They are responsible for important mortality, which makes them a public health problem (Ndiaye et al. 2009; Tournier et al. 2014). Few series in the literature have attempted to describe the epidemiology of APIs, particularly related to RTAs (Cheynel et al. 2011; Haddad et al. 2015; Helmi et al. 2001).

For more than 20 years, the Rhone Registry of Victims from Road Traffic Accidents (Registre des Victimes d' Accidents de la Route du Rhône $=$ ReVARRhône) has been collecting exhaustive data from all medical facilities in the French Rhone department on victims of RTAs (Gadegbeku et al. 2010).

The objective of this study was to describe the frequency and characteristics of abdominopelvic trauma from this registry and to study the risk factors among several available variables.

\section{Methods}

\section{Overview of the Rhône Registry}

The Rhone Registry, certified by the French National Committee of Registries, is a unique model in Europe; since 1995 it has been collecting data pertaining to the victims of road traffic accidents (Gadegbeku et al. 2010). It is part of the French Institute of Transport, Development and Road Network Science and Technology (Institut Français des Sciences et Technologies des Transports, de l'Aménagement et des Réseaux, IFSTTAR). Its function is to perform the continuous recording of all physically injured victims due to RTAs involving at least one moving vehicle (including skates and skateboards) and occurring in the geographic area of the Rhône department, with a population of $1,779,845$ inhabitants (2013 data). The majority of the victims were residents of the department. 
The collection is based on 245 public and private health facilities dealing with trauma care: Fire and rescue aid services, prehospital care services, emergency departments, displacement, resuscitation and intensive care, surgical and medical departments, forensic medicine, and rehabilitation, including in neighboring departments. Various types of information are collected regarding the patient, the accident, the lesions, and outcomes. Each victim has a unique identification number. Victims or their families are asked whether it is necessary to supplement some missing data. The registry team is in charge of centralization, verification of the data from different sources about the same accident or victim, coding, storage and filing, and statistical analysis. The Abbreviated Injury Scale (AIS 90) was used to code all injuries (Association for the Advancement of Automotive Medicine 1990). The Maximum Abbreviated Injury Scale (MAIS) is the highest (maximum) immediate gravity score among all the injuries. The aims of this registry, used by the public services, are to improve knowledge of traffic accidents and to help decrease the number and gravity of these accidents.

\section{Study design}

We conducted an observational study from January 11996 to December 31, 2013. During this time frame, all victims with an abdominopelvic injury, including diaphragm and pelvic bone, were analyzed (AIS codes $\mathrm{R}=5$ for the abdomen, 4.4 .06 for the diaphragm, and 8.5.26 + 8.5.28 + 8.5.30 for the pelvic bone). Several data were extracted and analyzed: Demographics (sex, age), characteristics of the accident (type of user, protection devices, antagonist, type of road, time), anatomical lesions, and elements of gravity (Injury Severity Score [ISS], AIS, mortality).

\section{Statistical analysis}

Statistical analyses were performed using Statistical Analysis System 9.4 (SAS Institute Inc., Cary, NC). A $P$ value of .05 was used to define statistical significance. Chi-square test, or Fisher's exact test when the cell sizes were not large enough, was used to compare the equality of proportions. Logistic regression analysis was used to explain the presence of an API depending on different factors.

\section{Results}

\section{Overall characteristics}

During the time frame of the study, there were 204,227 forms collected, which were related to 143,027 accidents and a total of 162,695 victims. Of these victims, 10,165 presented with
APIs (6.2\%). Mean annual incidence of APIs was 565 victims (34/100,000 inhabitants in Rhône).

The mean age was 32.2 years; those aged 20-24 years were most frequently involved. Overall, $62.4 \%$ of APIs involved men (6,347 men and 3,815 women, ratio 1.7$)$.

Almost half of the victims were car drivers (46\%), and around one quarter were motorcyclists (24.7\%), followed by pedestrians (12.8\%), bicyclists (11\%), and rarely other vehicles. The most common antagonist was a car (55.4\%), followed by no antagonist (22.4\%), fixed obstacle (9.3\%), and truck or bus (8.2\%).

Severe APIs (AIS 3+) involved 2,676 victims (26.3\% of APIs and $1.6 \%$ of the whole registry). The mean ISS was 8.7 (24.6 for the AIS $3+$ subgroup). The mortality rate for APIs was 5.6\% (1.1\% in the entire registry), with a majority of deaths occurring on scene (314 patients, 55.3\%) or during the first $24 \mathrm{~h}$ (118 patients, 20.8\%).

Concomitant injured body areas, frequencies, and AIS gravity are presented in Table 1 . The mean number of injuries was 2.5 per victim. The most frequently extra-abdominal-associated injured zones included lower limbs (with the exception of the pelvic bone), chest (with the exception of the diaphragm), upper limbs, head, and spine. Among the most severe AIS 4+ patients, chest was the most frequently involved (41\%), followed by head (27\%) and abdomen (21\%). We found the same frequency for fatalities in our study when data were available due to a forensic examination or a postmortem computed tomography (CT) scan. In patients with both severe AIS 3+ cerebral and AIS 3+ abdominopelvic injuries, the mortality rate increased to $65 \%$.

The majority of lesions were superficial ones, involving skin and soft tissues $(n=6,388 ; 54.4 \%)$. There were 2,322 pelvic bone injuries and 72 diaphragm injuries. Among the intra-abdominal lesions ( $n=2,497 ; 21.3 \%$ ), the large solid organs were the most commonly injured: spleen, liver, and kidneys (Figure 1). Road user type had no significant impact on the distribution of most of the injured organs. On the other hand, injuries to external genitalia ( $n=462 ; 3.9 \%)$ occurred almost exclusively among 2-wheeler drivers.

\section{Impact of wearing a seat belt among car drivers}

Among the car users $(n=4,675), 75.1 \%$ wore a seat belt, $12.1 \%$ did not, and this information was missing in $12.8 \%$. Wearing a seat belt appeared to be protective against severe lesions: AIS 2 to 5 injuries and mortality were significantly higher among nonbelted victims.

Distribution of the injuries showed some differences depending on whether or not a seat belt was worn: Splenic, renal, pancreatic, adrenal, diaphragmatic, and retroperitoneal injuries

Table 1. Concomitant injuries with ISS according to MAIS.

\begin{tabular}{|c|c|c|c|c|c|c|c|}
\hline Body region & MAIS = 1 & MAIS $=2$ & MAIS = 3 & MAIS $=4$ & MAIS $=5$ & MAIS $=6$ & Total (AIS 4+) \\
\hline Head & 723 & 882 & 228 & 254 & 169 & 39 & $2,295(462)$ \\
\hline Face & 1,014 & 216 & 26 & 14 & 0 & 0 & 1,270 (14) \\
\hline Neck & 727 & 11 & 7 & 1 & 4 & 1 & $751(6)$ \\
\hline Chest & 1,311 & 214 & 621 & 508 & 162 & 44 & $2,860(714)$ \\
\hline Abdomen & 6,675 & 960 & 523 & 275 & 73 & 9 & $8,515(357)$ \\
\hline Spine & 1,373 & 482 & 114 & 4 & 43 & 20 & $2,036(67)$ \\
\hline Upper limb & 1,443 & 861 & 395 & 0 & 0 & 0 & $2,699(0)$ \\
\hline Lower limb & 1,730 & 1,384 & 1,154 & 71 & 29 & 0 & $4,368(100)$ \\
\hline Skin & 730 & 2 & 1 & 1 & 2 & 1 & 737 (4) \\
\hline
\end{tabular}




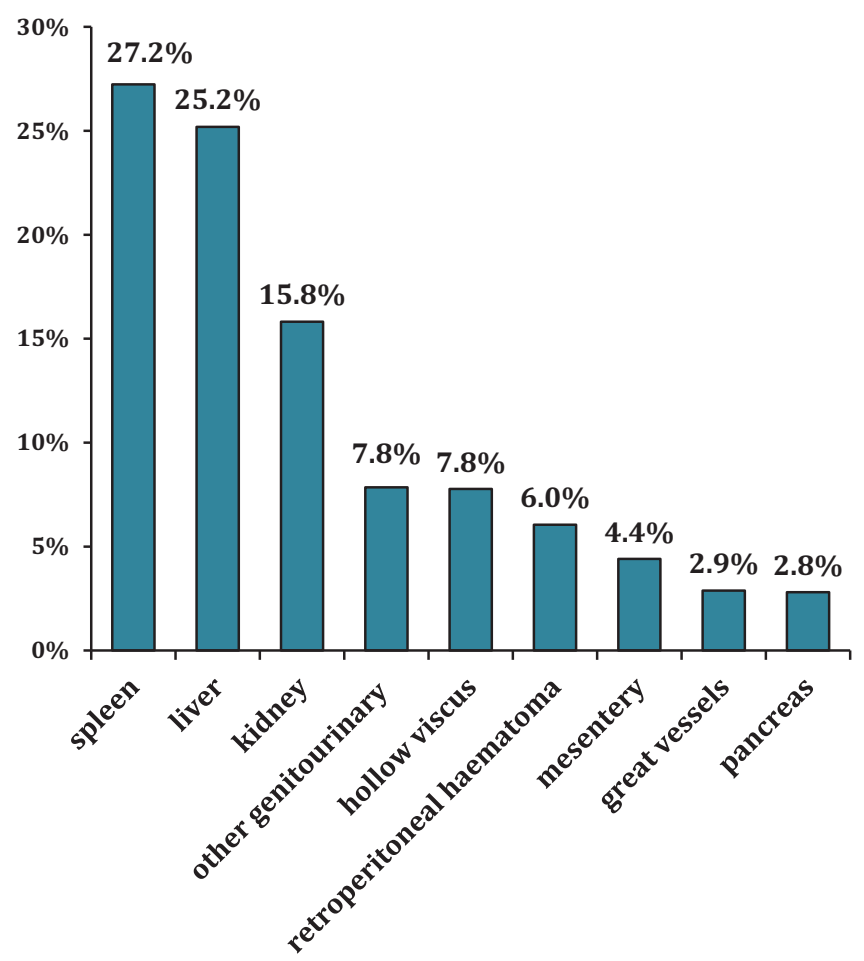

Figure 1. Overall distribution of internal abdominal injuries ( $n=2,497$ victims).

were more frequent among nonbelted users, whereas differences for the other organs, including liver or hollow viscous injuries, were not significant.

\section{Hospitalization in the intensive care unit for severe APIs}

Among AIS $3+$ severe APIs $(n=2,676), 1,537$ people $(57.4 \%)$ were admitted to the intensive care unit. During the past 2 years of our study (2012-2013), analysis of medical reports from the intensive care unit for AIS $3+$ injuries $(n=181)$ revealed that 38 patients $(21 \%)$ required a hemostatic surgical procedure, $19(10.5 \%)$ had a radiological arterial embolization, and the majority $(124,68.5 \%)$ could be treated with nonoperative management.

\section{Analysis of risk factors for APIs}

A multivariate model was used to ensure that the interaction between all factors was taken into account (for example, motorcyclists are mostly men, whereas women are more often belted (Gadegbeku et al. 2006; Table 2).

Victims of APIs were more often men (odds ratio $[\mathrm{OR}]=$ $1.111 ; P=.005)$. Compared to the reference group of $26-$ to 35 -year-olds, children $<15$ years old were less affected $(\mathrm{OR}=$ $0.835 ; P=.006)$; whereas those older than 46 years old were increasingly more affected $(P<.001$ for each). Pedestrians and 2 -wheeler users had greater risk compared to car drivers $(\mathrm{OR}>$ 2 with $P<.001)$. The absence of obstacles was a protective factor $(\mathrm{OR}=0.638 ; P<.001)$, whereas a fixed obstacle or a heavy goods vehicle was at higher risk than a car for antagonists $(P<$ $.001)$. Regarding the road type, compared to a city street, the risk of having an API was higher on a road $(\mathrm{OR}=2.174 ; P<.001)$, not significant for a highway $(P=.253)$, and lower for all other types such as a path, a parking area, etc. $(\mathrm{OR}=0.838 ; P<.001)$. Analysis of the time of the accident revealed that there was a lower risk of API between 8 a.m. and 3 p.m.; on the other hand, the negative impact of nighttime from 8 p.m. to 7 a.m. was clear $(P<.001)$.

A severe AIS 3+ injury to the thorax (excluding diaphragm), head (AIS 3+), or spine (AIS 2+) was a major risk factor of associated with API (all OR $>10 ; P<.001$ ). Finally, not wearing a seat belt was also a significant risk factor $(\mathrm{OR}=2.556 ; P<.001)$.

\section{Discussion}

Our study reveals a $6.2 \%$ incidence of abdominopelvic injuries within the whole registry. Other series in the literature reported higher rates, between 11 and $18 \%$, but were either limited to inhospital series or included other causes of trauma, making them difficult to compare (American College of Surgeons Committee on Trauma [ACSCOT] 2016; Arumugam et al. 2015; Haddad 2015; Helmi et al. 2001). Cheynel et al. (2011) reported, in a series that also included prehospital care interventions, a $9.3 \%$ incidence. The Rhône Registry also collects data pertaining to untransported self-consulting patients, frequently with minor lesions. Moreover, our study commenced 20 years ago, radiological exams were not well organized, and abdominal lesions were probably often underdiagnosed, whereas the current systematization of total body CT scan allows a better detection and characterization of injuries. Finally, the Rhône department is a small and urban area, where the gravity of RTAs is less severe than in the rest of the country.

The incidence of APIs in the recent years of our study decreased to $24.5 / 100,000$ inhabitants in 2013. At the same time, the overall incidence of RTAs has been continuously decreasing, due to French laws regarding speeding and driving under the influence of alcohol from the early 2000s, combined with advances in car engineering and road safety, similar to other countries (Ernstberger 2015).

The predominance of young men constitutes constant data in road traffic accident registries, even if a shift toward an increase in the age of victims can be observed (ACSCOT 2016; Lapostolle et al. 2009).

The ISS was used to describe the severity of injuries. The new ISS (NISS), using the 3 most severe injuries regardless of body region, is a better predictor of survival and could have been adapted here to take into account the association of multiple abdominal injuries (Brenneman et al. 1998). According to the period of data collection, the ISS was the most easily available scale.

Abdominopelvic injuries are quite rare and also rarely severe, but our study confirms that they remain associated with a very significant mortality: $5.6 \%$ vs. $1.1 \%$ in the rest of the registry $(P<.0001$; Cheynel et al. 2011). Mortality occurs mostly on scene and during the "golden hour," which can be explained by uncontrollable hemorrhaging and severe head trauma. Only $10 \%$ of the mortality is related to APIs, after thoracic and head injuries. The association of severe cerebral and abdominopelvic injuries was associated with a mortality rate of $65 \%$. This confirms the well-known deleterious combination of severe hemorrhage, such as severe abdominal injury, and a cranioencephalic injury (Cheynel et al. 2011; Haddad et al. 2015). However, in 
Table 2. Risk factors for abdominopelvic injuries: Odds ratios estimated from logistic regression including 162,695 victims of traffic accidents between 1996 and 2013.

\begin{tabular}{|c|c|c|c|c|c|c|}
\hline & \multicolumn{3}{|c|}{ Univariate analysis } & \multicolumn{3}{|c|}{ Multivariate analysis } \\
\hline \multicolumn{7}{|l|}{ Sex } \\
\hline Female & 1 & - & - & 1 & - & - \\
\hline \multicolumn{7}{|l|}{ Age (years) } \\
\hline $0-15$ & 0.833 & [0.738-0.941] & .003 & 0.835 & [0.735-0.949] & .006 \\
\hline $46-55$ & 1.354 & {$[1.198-1.531]$} & $<.001$ & 1.302 & {$[1.149-1.475]$} & $<.001$ \\
\hline $56-65$ & 1.675 & [1.453-1.932] & $<.001$ & 1.616 & [1.396-1.870] & $<.001$ \\
\hline $66-75$ & 2.356 & [2.016-2.754] & $<.001$ & 2.215 & {$[1.884-2.604]$} & $<.001$ \\
\hline$>76$ & 3.174 & {$[2.706-3.723]$} & $<.001$ & 2.774 & {$[2.343-3.285]$} & $<.001$ \\
\hline \multicolumn{7}{|l|}{ Type of user } \\
\hline Pedestrian & 2.724 & [2.481-2.990] & $<.001$ & 3.188 & [2.868-3.543] & $<.001$ \\
\hline Car & 1 & - & - & - & - & - \\
\hline Truck/bus & 1.911 & [1.682-2.171] & $<.001$ & 2.005 & [1.759-2.287] & $<.001$ \\
\hline Fixed obstacle & 1.444 & [1.311-1.592] & $<.001$ & 1.539 & [1.389-1.705] & $<.001$ \\
\hline Other & 1.108 & [0.983-1.249] & .094 & 1.020 & [0.902-1.152] & .754 \\
\hline \multicolumn{7}{|l|}{ Road network } \\
\hline Highway & 0.840 & [0.741-0.951] & .006 & 1.080 & [0.947-1.233] & .253 \\
\hline Rural road & 1.842 & [1.695-2.003] & $<.001$ & 2.174 & [1.991-2.375] & $<.001$ \\
\hline City street & 1 & - & - & - & - & - \\
\hline Other & 0.529 & [0.484-0.579] & $<.001$ & 0.838 & [0.759-0.925] & $<.001$ \\
\hline \multicolumn{7}{|l|}{ Time of accident } \\
\hline 12:00-3:00 a.m. & 1.711 & [1.492-1.961] & $<.001$ & 2.170 & {$[1.882-2.503]$} & $<.001$ \\
\hline 4:00-7:00 a.m. & 1.260 & [1.119-1.418] & $<.001$ & 1.318 & [1.167-1.489] & $<.001$ \\
\hline 8:00-11:00 a.m. & 0.877 & [0.791-0.972] & .013 & 0.802 & [0.722-0.891] & $<.001$ \\
\hline 12:00-3:00 p.m. & 0.909 & [0.826-1.001] & .053 & 0.899 & [0.815-0.990] & .031 \\
\hline
\end{tabular}

Note: $\mathrm{OR}=$ odd ratio; $\mathrm{AOR}=$ adjusted odd ratio.

this study, it was not possible to systematically identify the reason for death, which was mainly due either to cerebral injuries or to massive bleeding from the chest, abdomen, or pelvis. Because road traffic accidents are considered to be a cause of death in their own right, autopsies are rarely performed in France for such fatalities (Ndiaye et al. 2009). In those cases, anatomical injuries could be identified with an external physical examination only or a virtual forensic exam with a CT scan in hospitals where this protocol existed.

Soft tissue injuries, poorly studied because of their frequent benignity, account for more than half of lesions. The pelvic bone, as reported by Haddad et al. (2015), is the most frequently injured organ among APIs. Its overall incidence within the whole registry is $1.4 \%$. Due to high-velocity trauma, which poses a high risk of associated lesions, fractures, or disruptions of the pelvic bone, is responsible for increased mortality (Sathy et al. 2009). As expected for blunt abdominal trauma, solid organs are the most frequently injured intra-abdominal organs: First the spleen and liver in similar proportions, followed by the kidneys (Arumugam et al. 2015; Cheynel et al. 2011; Haddad et al. 2015; Helmi et al. 2001). External genitalia are relatively frequently involved (3.9\% of all APIs), mostly among 2 -wheeler drivers, and remain anecdotic among other drivers.

The seat belt is a protection device that contributes to decreasing the severity of road traffic accidents, and this study logically confirms its beneficial effect (Gadegbeku et al. 2010;
Nash et al. 2016). Not wearing a seat belt is not only an independent risk factor of having an API in the multivariate model, but, among victims of API, the seat belt is a protective factor against severe lesions and mortality. We observe a significant decrease in most internal solid organ injuries due to the absence of a seat belt but there is no increase in hollow viscus injuries, although commonly described in the literature (Nash et al. 2016; Sharma et al. 2009). Seat belt marks are not specifically documented in our registry but are anatomically included with the other abdominal cutaneous hematomas of the AIS scale. Thus, we could not study the relation between seat belt mark as such and APIs but only the relation between being restrained (with or without a seat belt sign) and APIs. This is reported as a sign of gravity, related to the violence of the accident, but it is not specific to hollow viscus injuries (Velhamos et al. 1999).

In multivariate analysis, all factors in our analysis were significantly correlated with the risk of having an API. The type of vehicle or locomotion is the most determinant factor: 2-Wheelers and pedestrians are more exposed, probably due to less protection. No third party is a protective factor, in contrast to the kinetics added by an antagonist. A growing vulnerability with age also appears (Brasel and Nirula 2005). The impact of place and time results in a maximum risk on a rural road, as well as at night, and may be related to the violence of impacts under possible conditions of high speed, frontal antagonists, and low visibility. The specific high risk linked to the male sex may be 
explained by a higher average speed or a greater risk behaviors (alcohol or narcotics); these factors are unfortunately not available in the registry (Martin et al. 2004). According to our study, the user who would be most protected against API is a belted woman driving a car during daytime on a city street, whereas an elderly pedestrian or a motorized 2-wheeler hitting a heavy vehicle at night on a rural road appears to be much more exposed to the occurrence of an API, keeping in mind that this is only a statistical association but that these might be proxy variables for other unrecorded variables, like speed, for instance.

For more than 20 years, the Rhône Registry has provided an exhaustive census of all victims of a traumatic injury after a traffic accident involving a means of locomotion and occurring on a road open to traffic. To our knowledge, this unique model has no equivalent at a national level or in Europe. In the United States, the National Trauma Data Bank is a national registry that is administered by the American College of Surgeons Committee on Trauma (ACSCOT 2016). It is the largest cohort in the world, with more than 7 million registered casualties (more than 861,000 inclusions in 2015), with data coming from 747 U.S. and Canadian volunteer trauma centers. The Rhône Registry does not suffer from hospital admission bias because it is based on the totality of the department's emergency and care services. It aims at completeness in both public and private hospital networks (Gadegbeku et al. 2006). However, some victims may not be included. Completeness is estimated at $73 \%$ for minor and moderately wounded survivors and at $87 \%$ for seriously wounded survivors (Amoros et al. 2007). Police statistics, which are the basis of road safety studies, underestimate the number of victims injured in traffic accidents (Amoros et al. 2006). In addition, victims who directly consult a physician or take care of themselves are not recorded in the registry.

The information provided by the registry has some limitations. First, due to the medical source, it is not possible to assess detailed data about mechanisms such as velocity, rollover, impact direction, etc. Velocity and rollover were shown to be independently associated with the presence of abdominal injury (Brasel and Nirula 2005), whereas the side of impact might induce significant differences in the type of injuries and outcomes (Charyk et al. 2013). Alcohol, as well as other drugs, is another significant factor in RTAs that has been an important area for injury prevention efforts (Missoni et al. 2012). These data are unfortunately not available in the registry but have been the subject of several parallel studies by our team (Martin et al. 2017). Lastly, the main limitation may be the lack of directly available data regarding physiology and the management of trauma, which could have been informative and potentially relevant with severe hemorrhagic APIs (Cheynel et al. 2011; Haddad et al. 2015). It was still possible to perform a partial analysis over the past 2 years, by searching records of patients with severe AIS 3+ APIs and admitted to an intensive care unit. This confirmed the importance of nonoperative management even for severe lesions, due to progress in radiology and intensive care.

However, the anatomical descriptions are based on information from several departments, enabling very precise and fine data aggregation. The size, completeness, and accuracy of the registry make it a reliable epidemiological tool, which is used by governments or industries to improve knowledge and the prevention of road traffic accidents.
Our study confirms that the incidence of APIs in RTAs is low, but that they are responsible for an increased mortality. The pelvic bone is frequently affected in more than one fifth of cases; spleen and liver are the most frequently injured organs, each one in more than one quarter of the cases. We did not find any increased risk of hollow viscus injuries due to the seat belt, which appears to be a significant protective factor for severe lesions. Our statistical analysis reveals that a belted female car driver during daytime in town could be the best protected against abdominopelvic injuries. Further information about physiology or treatment would be relevant in the future for a better comprehensive clinical approach to those injuries.

\section{Acknowledgments}

The authors thank all of the people who took part in data collection and filing for the Association for the Registry of Victims of Road-Traffic Accidents in Rhône (ARVAC) and the French Institute of Science and Technology for Transport, Spatial Planning, Development and Networks (IFSTTARUMRESTTE).

\section{References}

American College of Surgeons Committee on Trauma. National Trauma Data Bank 2016 Annual Report. 2016. Available at: https://www. facs.org/ /media/files/quality\%20programs/trauma/ntdb/ntdb\%20an nual\%20report\%202016.ashx. Accessed February 28, 2018.

Amoros E, Martin JL, Laumon B. Under-reporting of road crash casualties in France. Accid Anal Prev. 2006;38:627-635.

Amoros E, Martin JL, Laumon B. Estimating non-fatal road casualties in a large French county, using the capture-recapture method. Accid Anal Prev. 2007;39:483-490.

Arumugam S, Al-Hassani A, El-Menyar A, et al. Frequency, causes and pattern of abdominal trauma: a 4-year descriptive analysis. J Emerg Trauma Shock 2015;8:193-198.

Association for the Advancement of Automotive Medicine. The Abbreviated Injury Scale, 1990 Revision. Des Plaines, IL: Author; 1990.

Brasel KJ, Nirula R. What mechanism justifies abdominal evaluation in motor vehicle crashes? J Trauma. 2005;59:1057-1061.

Brenneman FD, Boulanger BR, McLellan BA, Redelmeier DA. Measuring injury severity: time for a change? J Trauma. 1998;44:580-582.

Charyk ST, McClafferty K, Shkrum M, Comeau JL, Gilliland J, Fraser DD. A comparison of injuries, crashes, and outcomes for pediatric rear occupants in traffic motor vehicle collisions. J Trauma Acute Care Surg. 2013;74:628-633.

Cheynel N, Gentil J, Freitz M, et al. Abdominal and pelvic injuries caused by road traffic accidents: characteristics and outcomes in a French cohort of 2,009 casualties. World J Surg. 2011;35:1621-1625.

Ernstberger A, Joeris A, Daigl M, et al. Decrease of morbidity in road traffic accidents in a high income country-an analysis of 24,405 accidents in a 21 year period. Injury. 2015;46:S135-S143.

Gadegbeku B, Chiron M, Ndiaye A, Laumon B. Victimes d'accidents de la circulation: quelles évolutions? Registre du Rhône, France, 1996-2008 [Victims of road-traffic accidents: what has changed? Rhône registry, France, 1996-2008]. Bull Epidémiol Hebd. 2010;47:477-484.

Gadegbeku B, Ndiaye A, Chiron M. Séquelles majeures en traumatologie routiére, registre du Rhône, 1996-2003 [Major incapacity after roadtraffic traumatisms, Rhône registry, France, 1996-2003]. Bull Epidémiol Hebd. 2006;36:267-272.

Haddad SH, Yousef ZM, Al-Azzam SS, et al. Profile, outcome and predictors of mortality of abdomino-pelvic trauma patients in a tertiary intensive care unit in Saudi Arabia. Injury. 2015;46:94-99.

Helmi I, Hussein A, Ahmed AH. Abdominal trauma due to road traffic accidents in Qatar. Injury. 2001;32:105-108. 
Lapostolle A, Gadegbeku B, Ndiaye A, et al. The burden of road traffic accidents in a French departement: the description of the injuries and recent changes. BMC Public Health. 2009;9:386.

Martin J-L, Gadegbeku B, Wu D, Viallon V, Laumon B. Cannabis, alcohol and fatal road accidents. PLoS ONE. 2017;12:e0187320.

Martin J-L, Lafont S, Chiron M, Gadegbeku B, Laumon B. Différences entre les hommes et les femmes face au risque routier [Differences between males and females in road-traffic accidents]. Rev Epidemiol Sante Publique. 2004;52:357-367.

Missoni E, Božić B, Missoni I. Alcohol-related road traffic accidents before and after passing of the Road Traffic Safety Act in Croatia. Coll Antropol. 2012;4:1483-1489.

Moore PG. Abdominal and pelvic injuries. In: Oestern H-J, Trentz O, Uranues S, eds. Trauma Surgery. Vol. 1. Springer-Verlag; 2011. Available at: http://hannaziegler.tripod.com/general/icu/oh/ohc071.pdf. Accessed February 28, 2018.

Nash NA, Okoye O, Albuz O, et al. Seat belt use and its effect on abdominal trauma: a national trauma databank study. Am Surg. 2016;82:134-139.
Ndiaye A, Chambost M, Chiron M. The fatal injuries of car drivers. Forensic Sci Int. 2009;184:21-27.

Sathy AK, Starr AJ, Smith WR, et al. The effect of pelvic fracture on mortality after trauma: an analysis of 63,000 trauma patients. J Bone Joint Surg Am. 2009;91:2803-2810.

Sharma OP, Oswanski MF, Kaminski BP, et al. Clinical implications of the seat belt sign in blunt trauma. Am Surg. 2009;75:822-827.

Smith J, Caldwell E, D'Amours S, Jalaludin B, Sugrue M. Abdominal trauma: a disease in evolution. Aust N Z J Surg. 2005;75: 790-794.

Tournier C, Charnay P, Tardy H, et al. A few seconds to have an accident, a long time to recover: consequences for road accident victims from the ESPARR cohort 2 years after the accident. Accid Anal Prev. 2014;72:422-342.

Velmahos GC, Tatevossian R, Demetriades D. The "seat belt mark" sign: a call for increased vigilance among physicians treating victims of motor vehicle accidents. Am Surg. 1999;65: 181-185. 